\title{
Short communication: Limit feeding dairy heifers: Effect of feed bunk space and provision of a low-nutritive feedstuff
}

\author{
A. M. Greter, B. L. Kitts, and T. J. DeVries ${ }^{1}$ \\ Department of Animal and Poultry Science, University of Guelph, Kemptville Campus, 830 Prescott Street, Kemptville, ON, K0G 1J0, Canada
}

\begin{abstract}
The objectives of this study were to examine the behavioral effects of providing limit-fed dairy heifers an increased amount of feed bunk space compared with recommended feed bunk allowance, and to determine if the effects of provision of extra bunk space would be comparable to those seen when limit-fed heifers are provided a low-nutritive feedstuff. Twelve Holstein dairy heifers $(381.1 \pm 44.8 \mathrm{~d}$ of age, $417.3 \pm 47.9 \mathrm{~kg})$, divided into groups of 4 , were exposed to each of 3 treatments using a $3 \times 3$ Latin square design with 7 -d periods. The treatments were (1) $0.68 \mathrm{~m}$ of feed bunk space/ heifer (TMR-0.68), (2) $0.34 \mathrm{~m}$ of feed bunk space/heifer (TMR-0.34), and (3) $0.34 \mathrm{~m}$ of feed bunk space/heifer with an additional $0.34 \mathrm{~m}$ of feed bunk space available for free-choice straw (TMR-S). The total mixed ration was fed once daily at a restricted level $(1.83 \%$ of body weight) and contained (dry matter basis) $19.9 \%$ alfalfa/ grass haylage, $20.1 \%$ corn silage, $49.6 \%$ high-moisture corn, and $10.4 \%$ protein supplement. Group dry matter intake (DMI) was recorded daily. Behavior at the feed bunk was recorded for the last $4 \mathrm{~d}$ of each treatment period. Due to the provision of straw, DMI was highest on the TMR-S treatment compared with the other treatments $(9.4$ vs. $7.8 \mathrm{~kg} / \mathrm{d})$. Heifers spent the most time feeding when on the TMR-S treatment (147.7 $\mathrm{min} / \mathrm{d}$ ), with no difference in feeding time between the limit-fed TMR treatments $(64.5 \mathrm{~min} / \mathrm{d})$. Within the TMR-S treatment, feeding time on the straw was $76.9 \mathrm{~min} / \mathrm{d}$; thus, the rate of consumption of only the TMR was similar across all treatments. Unrewarded time at the feed bunk (when no feed was present) did not differ between treatments. Heifers did not differ in competitive behavior when on the limit-fed TMR treatments (13.1 displacements/heifer per day). However, while on the TMR-S treatment, heifers displaced each other more frequently (23.8 displacements/heifer per day) than while on the other 2 treatments. Overall, results suggest that neither increased feed bunk space
\end{abstract}

Received November 22, 2010.

Accepted February 7, 2011.

${ }^{1}$ Corresponding author: tdevries@uoguelph.ca nor provision of straw will reduce competition for, or slow consumption rates of, a limit-fed TMR. The provision of straw alongside a limit-fed TMR did increase DMI, which would contribute to further rumen fill, and allowed heifers to increase their time spent feeding throughout the day.

Key words: limit feeding, dairy heifer, feeding behavior, feed bunk space

\section{Short Communication}

Limit feeding of replacement dairy heifers is a feeding management strategy that is gaining popularity with dairy producers. The use of limit feeding in dairy heifers allows for controlled growth rates, improved feed efficiency, reduced cost of feed per kilogram of gain, and a decrease in fecal excretion (Hoffman et al., 2007; Moody et al., 2007; Kitts et al., 2011). However, this practice raises some behavioral concerns, including increased vocalizations (Hoffman et al., 2007) and oral stereotypies (Redbo et al., 1996), which may be indicative of hunger and frustration, ultimately suggesting a reduction in welfare. Potential health concerns associated with limit feeding include increased standing time without eating (Hoffman et al., 2007; Kitts et al., 2011) and increased potential for the development of subacute ruminal acidosis (Moody et al., 2007).

Limit-fed dairy heifers require varied amounts of feed bunk space, depending on size and age, to achieve adequate ADG to meet target growth and calving age goals (Longenbach et al., 1999). Failure to provide adequate space results in an increase in attempts to feed, shorter duration of meals, less time spent feeding, and, ultimately, a decrease in overall ADG, as well as an increase in variability of ADG between individuals (Longenbach et al., 1999). At low levels of feed bunk space, it appears that limit-fed dairy heifers are highly motivated to compete for feed access. It could be hypothesized that providing additional space at the feed bunk may provide sufficient opportunity for all animals to feed simultaneously and, thus, aid in reducing this competition. Therefore, the objective of this study was to examine the behavior of limit-fed dairy heifers when provided with an increase in feed bunk space compared 
with recommended feed bunk allowance. In addition, we also set out to determine if the effects of provision of extra bunk space would be comparable to those seen when limit-fed heifers are provided a low-nutritive feedstuff, which has previously been demonstrated to increase feeding time, decrease inactive standing time, and maintain a targeted ADG (Kitts et al., 2011). The hypothesis was that both the addition of straw and the provision of additional feed bunk space would allow heifers to satisfy their foraging needs while minimizing competition.

Twelve Holstein dairy heifers were used in this study, which was conducted between November and December 2009. Animals were (mean \pm SD) $381.1 \pm 44.8 \mathrm{~d}$ of age, and weighed $417.3 \pm 47.9 \mathrm{~kg}$ at the beginning of the study. Over the course of the experiment, the animals gained $0.84 \mathrm{~kg} / \mathrm{d}$. Heifers were housed in 3 pens in the heifer research barn at the University of Guelph, Kemptville Campus (Kemptville, ON, Canada) and were managed according to the guidelines set by the Canadian Council on Animal Care (2009). The pens, located in a naturally ventilated cold barn, consisted of an indoor sand-bedded pack area $(3.6 \times 10.9 \mathrm{~m}$; width $\times$ depth $)$ and an outdoor concrete run $(3.6 \times 16.4 \mathrm{~m})$. Bedding material (fine-grain, washed sand) was replenished as needed. Feed bunks were located along the front of each pack area within each pen.

Before the beginning of the study, heifers were gradually acclimated to a reduced amount of a nutrient-dense TMR (Table 1) during a 10-d adaptation period. At the beginning of the adaptation period, heifers were fed the TMR ad libitum. Over the $10 \mathrm{~d}$, the amount of feed offered was incrementally decreased until heifers were fed the ration at a restricted level of $1.83 \%$ of BW. At this feeding rate, the ration, fed once daily at $1130 \mathrm{~h}$, was formulated to meet the nutrient requirements of a dairy heifer growing at $0.9 \mathrm{~kg} / \mathrm{d}$ (NRC, 2001). Heifers were given ad libitum access to trace mineral salt blocks (Windsor TM Stock Salt, The Canadian Salt Company Ltd., Pointe-Claire, Quebec, Canada). Water was available ad libitum through a water bowl in each pen.

The number of replicates required per treatment was determined through power analysis (Morris, 1999) for the primary response variables, including feeding behavior and DMI. Estimates of variation for these variables were based on previously reported values (Kertz and Chester-Jones, 2004; Hoffman et al., 2007; Kitts et al., 2011). Heifers were divided into 3 groups of 4 , which were balanced for weight and age. Following the adaptation period, heifers were subjected, using a $3 \times$ 3 Latin square design, to each of 3 treatments: (1) 0.68 $\mathrm{m}$ of feed bunk space/heifer (TMR-0.68), (2) $0.34 \mathrm{~m}$ of feed bunk space/heifer (TMR-0.34), and (3) 0.34 $\mathrm{m}$ of feed bunk space/heifer with an additional $0.34 \mathrm{~m}$ of feed bunk space/heifer available for free-choice straw (offered at $2.0 \mathrm{~kg}$ as-fed/heifer per day) (TMR-S). Heifers were kept on each treatment for a total of $7 \mathrm{~d}$, which included a $3-\mathrm{d}$ adaptation period to the treatment followed by a 4-d data collection period.

Group intakes were recorded daily by weighing the amount of feed offered and amount of feed refused (if any). These data were used to calculate daily DMI $(\mathrm{kg} / \mathrm{d})$ on a pen basis. Heifers were weighed on the same day each week to track ADG. Feeding and competitive behaviors were monitored using time-lapse video recorded continuously for the last $4 \mathrm{~d}$ of each treatment period. Heifers were recorded using 1 video camera (Panasonic WV-BP330, Osaka, Japan) per pen, a time-lapse cassette recorder (Panasonic AG-6740) and a video multiplexer (Panasonic WJ-FS 616). Video cameras were mounted $3.2 \mathrm{~m}$ above each feed bunk. Red lights $(100 \mathrm{~W})$ mounted adjacent to the cameras were used to facilitate recording at night. Individual

Table 1. Ingredient, chemical composition (mean \pm SD), and particle size (mean $\pm \mathrm{SD}$ ) of the treatment diet

\begin{tabular}{lc}
\hline Composition & Amount \\
\hline Ingredient, \% of DM $^{\text {Corn silage }}$ & \\
Grass/alfalfa haylage $^{2}$ & 20.1 \\
High-moisture corn $^{4}$ & 19.9 \\
Protein supplement $^{4,5}$ & 49.6 \\
Chemical composition & \\
DM, \% & 10.4 \\
OM, \% of DM & $56.7 \pm 1.5$ \\
CP, \% of DM & $94.0 \pm 0.1$ \\
ADF, \% of DM & $14.1 \pm 0.3$ \\
NDF, \% of DM & $17.0 \pm 1.1$ \\
NFC, \% of DM & $25.9 \pm 1.4$ \\
Particle size, ${ }^{7} \%$ & $50.8 \pm 1.8$ \\
Long & \\
Medium & $2.4 \pm 1.6$ \\
Short & $46.7 \pm 2.5$ \\
Fine & $40.4 \pm 3.4$ \\
\hline
\end{tabular}

${ }^{1}$ Chemical composition of corn silage (DM basis) was $8.1 \pm 0.2 \% \mathrm{CP}$, $19.8 \pm 0.8 \% \mathrm{ADF}$, and $34.1 \pm 0.7 \% \mathrm{NDF}$.

${ }^{2}$ Chemical composition of grass/alfalfa haylage (DM basis) was $17.5 \pm$ $0.3 \% \mathrm{CP}, 36.6 \pm 1.0 \% \mathrm{ADF}$, and $45.3 \pm 0.8 \% \mathrm{NDF}$.

${ }^{3}$ Chemical composition of high-moisture corn (DM basis) was $8.3 \pm$ $0.4 \% \mathrm{CP}, 4.7 \pm 0.7 \% \mathrm{ADF}$, and $12.6 \pm 1.1 \% \mathrm{NDF}$.

${ }^{4}$ Chemical composition of the protein supplement (DM basis) was 39.4 $\pm 0.6 \% \mathrm{CP}, 11.0 \pm 1.4 \% \mathrm{ADF}$, and $16.1 \pm 1.6 \% \mathrm{NDF}$.

${ }^{5}$ Supplied by Ritchie Feed \& Seed Inc. (Ottawa, ON, Canada), containing (on as-is basis): $30.3 \%$ soybean meal, $24.2 \%$ Tri-Pro Gold (TriCounty Protein Corp., Winchester, ON, Canada), 16.5\% corn gluten meal, $11.0 \%$ canola meal, $5.9 \%$ ground limestone, $5.8 \%$ trace mineral/vitamin premix, $4.1 \%$ sodium bicarbonate, and $2.2 \%$ cobaltizediodized salt.

${ }^{6}$ Values were obtained from chemical analysis of TMR samples; NFC $=100-(\% \mathrm{CP}+\% \mathrm{NDF}+\%$ fat $+\%$ ash $)$.

${ }^{7}$ Particle size determined by Penn State Particle Separator that has a 19-mm screen (long), 8-mm screen (medium), 1.18-mm screen (short), and a pan (fine). 
heifers were identified within each pen by their unique patterns. Digital photographs were taken of each animal's head and another showing a dorsal view of the back. These photos were used during video analysis to identify individuals within each pen. The amount of time spent feeding during the 4-d recording period was scored for individual heifers using instantaneous scan sampling every 10 min. For each scan, a heifer was recorded as feeding when its head was completely past the feed rail and over the feed. If all feed had been consumed, the visit was recorded as an unrewarded bout. As validated by Kitts et al. (2011), total time spent feeding and total time spent in unrewarded visits were then calculated by multiplying the number of scans by 10. Unrewarded time and time spent feeding were then calculated for each heifer for each day of the recording periods (min/d). Additionally, to detect changes in the diurnal pattern of feed bunk attendance, these scans were used to calculate the percentage of heifers at the feed bunk over the course of each 24-h period. Based on these diurnal patterns, we calculated feeding time for each heifer during the 1.5-h period (period of peak feeding activity) following the delivery of feed, during which all of the TMR was consumed.

Feed bunk competition, recorded as displacements from the feed bunk while feeding, was measured for the last 4-d of each treatment period. A displacement was recorded when a butt or a push from the actor (instigator) resulted in the complete withdrawal of the reactor's head from beneath the feed rail (DeVries et al., 2004). These observations were used to calculate the number of times each heifer was displaced from the feed bunk each day. Further, these data were used to calculate, according to DeVries et al. (2004), an index of success in agonistic interactions for each individual heifer. This index of success was calculated as follows: number of individuals subdominant to focal heifer/ number of individuals dominant to focal heifer + number of individuals subdominant to focal heifer $\times 100 \%$.

Representative grab samples of the TMR and straw were collected daily for DM and chemical analysis at the time of feed delivery during the recording days. Orts straw samples were also collected, when available, for DM analysis. Samples of the TMR components were taken weekly for DM and chemical analysis. Additionally, duplicate samples of the TMR, straw, and forage components were taken weekly for particle size analysis. All samples were immediately frozen at $-20^{\circ} \mathrm{C}$ until they were analyzed. Samples for particle size separation were separated using a 3 -screen $(19,8$, and 1.18 mm) Penn State Particle Separator (Kononoff et al., 2003). Samples were separated into 4 fractions: long $(>19 \mathrm{~mm})$, medium $(<19,>8 \mathrm{~mm})$, short $(<8,>1.18$ $\mathrm{mm})$, and fine $(<1.18 \mathrm{~mm})$ particles. After separation, the DM of each separated fraction was determined by forced air drying at $55^{\circ} \mathrm{C}$ for $48 \mathrm{~h}$. Dry matter content of samples taken for chemical analysis was determined by drying samples in a forced air oven at $55^{\circ} \mathrm{C}$ for 48 $\mathrm{h}$. These samples were then ground to pass through a 1-mm screen (Wiley mill, Arthur H. Thomas Co., Philadelphia, PA). The ground samples were then sent to Cumberland Valley Analytical Services Inc. (Maugansville, $\mathrm{MD})$ for analysis of $\mathrm{DM}\left(135^{\circ} \mathrm{C}\right.$; AOAC, 2000 : method 930.15), ash $\left(535^{\circ} \mathrm{C}\right.$; AOAC, 2000: method 942.05), ADF (AOAC, 2000: 973.18), NDF with heatstable $\alpha$-amylase and sodium sulfite (Van Soest et al., 1991), NFC, and CP $(\mathrm{N} \times 6.25$; AOAC 2000: method 990.03; Leco FP-528 Nitrogen Analyzer, Leco, St. Joseph, MI).

Preliminary screening of the data revealed that all dependent variables were normally distributed. For analyses of treatment effects, the pen was considered the experimental unit. To ensure that the 3 -d adaptation period allowed sufficient time for the animals to adapt to the treatments, a preliminary analysis of the effect of day within treatment period was conducted on the DMI, feeding, and competitive behavior data collected in the last $4 \mathrm{~d}$ of each treatment period. This analysis revealed no effect of day or day $\times$ treatment interaction. Therefore, DMI, feeding, and competitive behavior data were averaged for each pen across the $4 \mathrm{~d}$ of each treatment period. To test for differences among treatments, data were analyzed using the MIXED procedure of SAS (SAS Institute, 2003). The model included the fixed effect of treatment, the random effects of pen and period, and the residual error. All values reported are least squares means. The Tukey-Kramer method was used to adjust the probability differences between least squares means. Data for feed bunk attendance (\% of heifers feeding) were summarized by hour for each pen for each treatment period. To test for effect of treatment on feed bunk attendance patterns, these data were analyzed using the MIXED procedure of SAS (SAS Institute, 2003) treating hour as a repeated measure. The model included the fixed effects of treatment and hour and the random effects of pen and period. The variance-covariance structure was first-order autoregressive, according to best fit with Schwarz's Bayesian information criterion. Overall, treatment responses were tested using the pen as the experimental unit; however, we had a specific prediction that certain heifers would respond differently in their peak feeding activity based on their index of success. Thus, the effect of treatment on peak feeding activity was also evaluated using heifer as the observational unit and the heifers' index of success as a covariate. These data were analyzed using the MIXED procedure of SAS (SAS Institute, 2003); the model included the index of 
Table 2. Intake and behavior measures from growing dairy heifers on experimental treatments ${ }^{1}$

\begin{tabular}{lccccc}
\hline & \multicolumn{4}{c}{ Treatment ${ }^{2}$} \\
\cline { 2 - 3 } Item & TMR-0.68 & TMR-0.34 & TMR-S & SE & $P$-value \\
\hline DMI, kg/d & 7.8 & 7.8 & 9.4 & 0.1 & 0.001 \\
Feeding time, min/d & 64.6 & 64.4 & 147.7 & 6.6 & $<0.001$ \\
Peak ${ }^{3}$ feeding time, min/d & 65.2 & 64.2 & 70.8 & 4.9 & 0.9 \\
Unrewarded time, min/d & 39.6 & 36.0 & 24.6 & 6.9 & 0.4 \\
Displacements, no./d & 13.0 & 13.2 & 23.8 & 2.9 & 0.08 \\
Peak ${ }^{3}$ displacements, no./d & 13.0 & 13.2 & 15.1 & 2.4 & 0.5 \\
\hline${ }^{1}$ Data are averaged across 3 pens (4 heifers/pen) for 4 d on each treatment. & & \\
${ }^{2}$ Heifers were allowed (1) 0.68 m of bunk space (TMR-0.68), (2) 0.34 m of bunk space (TMR-0.34), or (3) 0.34 \\
m of bunk space for a limit-fed TMR and an additional 0.34 m of bunk space for straw (TMR-S). \\
${ }^{3}$ Peak feeding activity period = 1.5-h period immediately following feed delivery.
\end{tabular}

success as a covariate, the fixed effect of treatment, the random effects of heifer within pen and period, and the residual error. Significance was declared as $P \leq 0.05$ and trends were reported if $0.05<P \leq 0.10$.

The amount of TMR provided was restricted across treatment groups and, as a result, DMI was similar for the TMR-0.68 and TMR-0.34 treatments. However, DMI was more than $20 \%$ higher for the TMR-S treatment due to consumption of straw (Table 2). This is consistent with data from recent research wherein limit-fed heifers were offered straw alongside or mixed into their TMR (Kitts et al., 2011). The consumption of straw in addition to the limit-fed TMR indicates that restricting intake of TMR to $1.83 \%$ of $\mathrm{BW}$ or less is not sufficient to allow dairy heifers to become satiated.

Analysis of the diurnal feed bunk attendance of heifers revealed a treatment by hour interaction $(\mathrm{SE}=0.5$, $P<0.001 ;$ Figure 1), indicating the different feeding pattern exhibited by heifers while on the TMR-S treatment. A peak in feeding activity was seen immediately following feed delivery, regardless of treatment, which is consistent with the normal diurnal pattern of feeding behavior seen in young and adult cattle (DeVries and von Keyserlingk, 2005, 2009). Across treatments, a similar percentage of heifers were feeding at the bunk during the period of peak feeding activity following feed delivery, resulting in similar feeding times by heifers across treatments during this period (Table 2). This is not surprising as it was during this period of peak feeding activity that all heifers, regardless of treatment, consumed the entire allotment of TMR. Similarly, other researchers measuring feeding time of limit-fed heifers found that the TMR was completely consumed in just over $1 \mathrm{~h}$ following feed delivery (Hoffman et al., 2007; Kitts et al., 2011).

During this period of peak feeding activity, the frequency of displacements from the feed bunk was also similar between treatments (Table 2). Kitts et al. (2011) found a comparable level of competition between heifers when provided a limit-fed TMR alone or with straw alongside. Our prediction was that with increased bunk space, limit-fed heifers would compete less for feed than heifers given less bunk space. However, all treatments allowed for sufficient space, well within suggested guidelines for feed bunk allowance (Longenbach et al., 1999), for all heifers to access feed simultaneously (Figure 1). The similar frequency of displacements when the heifers were consuming the TMR suggests that they were highly motivated to simply consume the feed, rather than engage in competitive behavior (Kitts et al., 2011). However, an effect of index of success on peak feeding time $(P<0.001)$ was observed, with more dominant heifers spending more time feeding than those less dominant [peak feeding time $=(0.34$ $\times$ index of success $\left.)+49.7 ; \mathrm{R}^{2}=0.46\right]$. We did not observe an index of success $\times$ treatment interaction $(P$ $=0.9$ ), indicating that this effect of dominance on peak feeding time was consistent across treatments. Longenbach et al. (1999) suggested that when feed bunk space for 11.5- to 15.5-mo-old limit-fed heifers was less than $0.31 \mathrm{~m} /$ heifer, increased competition might have contributed to the increased variation in growth they observed. Based on those results, and that of the current study, it can be hypothesized that in situations of increased competition for a limit-fed ration, such as when feed bunk space is limited, domination of the feed bunk by certain animals could restrict DMI in subordinate heifers, leading to increased variability in ADG between heifers of differing social status. Further work is encouraged to address this hypothesis.

While on the TMR-0.34 and TMR-0.68 treatments, heifers consumed all their feed in just over $1 \mathrm{~h}$ (Table 2). Evidence from previous studies suggests that ad libitumfed dairy heifers will spend 3 to $5 \mathrm{~h}$ feeding throughout the day in an intensively raised setting when given the opportunity (Greter et al., 2008; DeVries and von Keyserlingk, 2009), suggesting that heifers in this study were not meeting their diurnal feeding requirements. In fact, it has been demonstrated that lactating dairy cattle are motivated to orally manipulate (consume) 


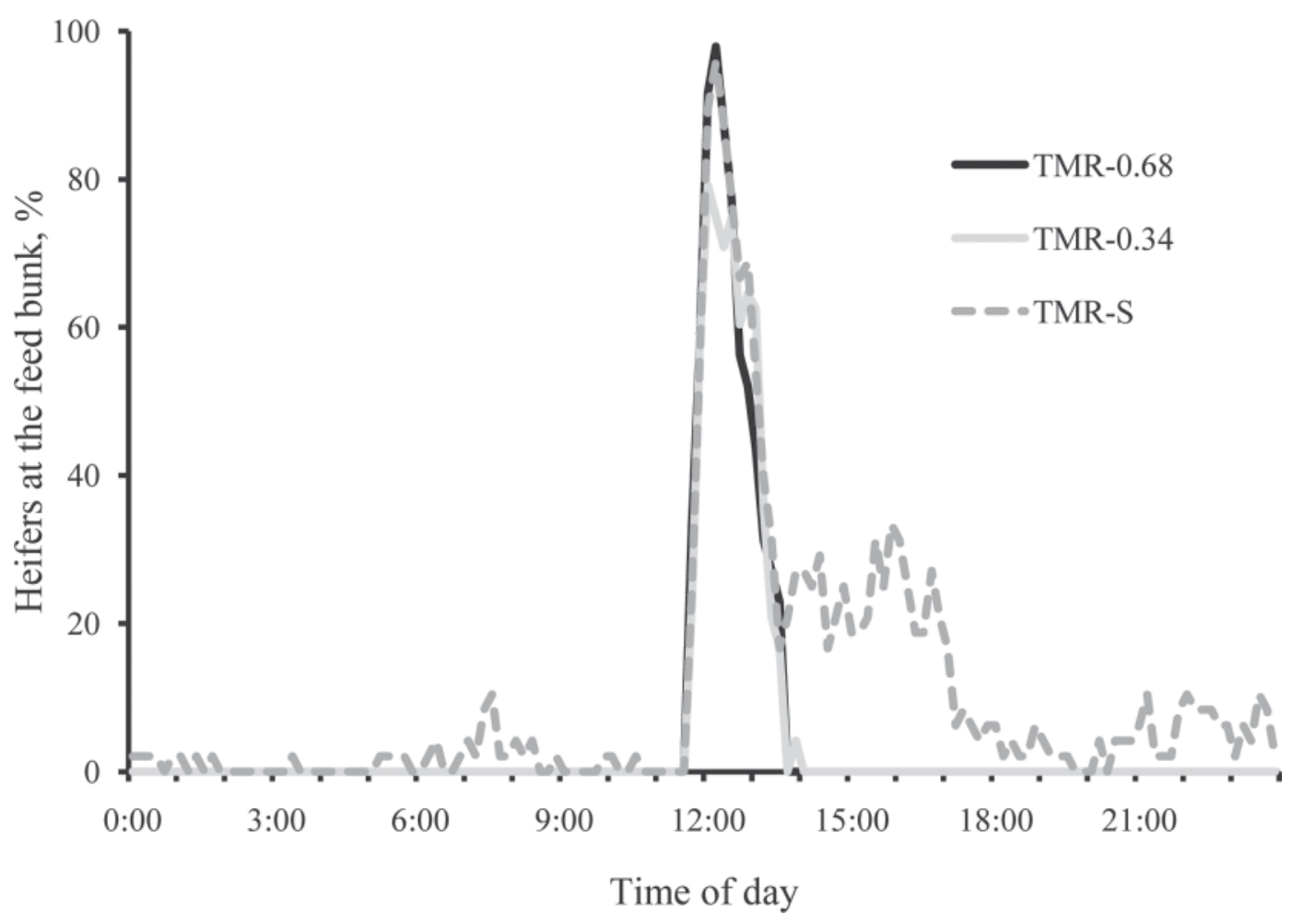

Figure 1. Percentage of heifers present at the feed bunk over a 24-h period (percentage for each 10-min interval during the day) for 3 treatments: (1) $0.68 \mathrm{~m}$ of bunk space/heifer (TMR-0.68), (2) $0.34 \mathrm{~m}$ of bunk space/heifer (TMR-0.34), or (3) $0.34 \mathrm{~m}$ of bunk space/heifer for TMR and an additional $0.34 \mathrm{~m}$ of bunk space/heifer for straw (TMR-S). Data were averaged across $4 \mathrm{~d}$ for 3 pens (4 heifers/pen) on each treatment.

feed whether the rumen is full or not, suggesting that the act of feeding itself (length of time spent feeding) has some effect on an animal's ability to feel satiated (Lindström and Redbo, 2000). In our study, heifers fed the limit-fed ration alone were not only limited in the time spent feeding but also unlikely to achieve sufficient rumen fill, possibly resulting in frustration due to a lack of satiety or a lack of substrate to manipulate. Once all the TMR was consumed, feeding activity was only possible on the TMR-S treatment for the rest of the day (Figure 1). Because of the consumption of the straw, feeding time was more than twice as long on the TMR-S treatment compared with the other treatments (Table 2). It is likely, therefore, that the consumption of straw alongside the limit-fed TMR contributed to greater satiety due to the consumption of sufficient bulk over a longer period throughout the day, as seen also in the Kitts et al. (2011) study.

The amount of unrewarded time at the feed bunk was similar across treatments (Table 2). A recent study with calves showed that visits to the milk feeder doubled in limit-fed calves compared with ad libitum-fed calves (De Paula Vieira et al., 2008). Those researchers concluded that unrewarded visits to the feeder could be used as an indicator of hunger. In our study, then, it could be suggested that some heifers on all treatments were expressing hunger behavior at some point during the day. Hunger is an indicator of negative welfare (von Keyserlingk et al., 2009) and, as such, limit feeding may pose a welfare concern. Interestingly, heifers on the TMR-S treatment spent a similar amount of unrewarded time at the feed bunk, despite having access to a low-nutritive feedstuff throughout the day, suggesting that heifers on this treatment were highly motivated to consume the nutrient-dense TMR rather than the straw. Further research on the motivation of limit-fed heifers to achieve satiety is needed to determine the importance of feeding behavior to these animals.

Overall, the provision of feeding space in excess of that which allows heifers to feed simultaneously had no effect on the feeding or competitive behavior of limitfed dairy heifers. Alternatively, the provision of straw alongside a limit-fed TMR did have a positive effect on dairy heifers fed a TMR in a limited amount because it resulted in greater DMI, which would contribute to further rumen fill, and an increase in time spent feeding throughout the day.

\section{ACKNOWLEDGMENTS}

We thank the staff and students at the University of Guelph, Kemptville Campus Dairy Education and 
Research Centre. In particular, we thank Megan Bruce, Albert Koekkoek, and Kerri Stevenson for their technical assistance with this project. Angela Greter was supported by a Natural Sciences and Engineering Research Council of Canada (NSERC) Canadian Graduate Scholarship. This project was funded through an Ontario Ministry of Agriculture, Food and Rural Affairs (OMAFRA)/University of Guelph Production Systems research grant. This project was also supported through contributions from the Canadian Foundation for Innovation (CFI) and the Ontario Research Fund.

\section{REFERENCES}

AOAC. 2000. Official Methods of Analysis. Vol. I. 17th ed. Association of Official Analytical Chemists International, Arlington, VA.

CCAC. 2009. Guidelines on the Care and Use of Farm Animals in Research, Teaching and Testing. Canadian Council on Animal Care, Ottawa, ON, Canada.

De Paula Vieira, A., V. Guesdon, A. M. de Passillé, M. A. G. von Keyserlingk, and D. M. Weary. 2008. Behavioural indicators of hunger in dairy calves. Appl. Anim. Behav. Sci. 109:180-189.

DeVries, T. J., and M. A. G. von Keyserlingk. 2005. Time of feed delivery affects the feeding and lying patterns of dairy cows. J. Dairy Sci. 88:625-631.

DeVries, T. J., and M. A. G. von Keyserlingk. 2009. Feeding method affects the feeding behavior of growing dairy heifers. J. Dairy Sci. 92:1161-1168.

DeVries, T. J., M. A. G. von Keyserlingk, and D. M. Weary. 2004. Effect of feeding space on the inter-cow distance, aggression, and feeding behavior of free-stall housed lactating dairy cows. J. Dairy Sci. $87: 1432-1438$.

Greter, A. M., T. J. DeVries, and M. A. G. von Keyserlingk. 2008. Nutrient intake and feeding behavior of growing dairy heifers: Effects of dietary dilution. J. Dairy Sci. 91:2786-2795.
Hoffman, P. C., C. R. Simson, and M. Wattiaux. 2007. Limit feeding of gravid Holstein heifers: Effect on growth, manure nutrient excretion, and subsequent early lactation performance. J. Dairy Sci. 90:946-954.

Kertz, A. F., and H. Chester-Jones. 2004. Guidelines for measuring and reporting calf and heifer experimental data. J. Dairy Sci. $87: 3577-3580$

Kitts, B. L., I. J. H. Duncan, B. W. McBride, and T. J. DeVries. 2011. Effect of the provision of a low-nutritive feedstuff on the behavior of dairy heifers fed a high-concentrate ration in a limited amount. J. Dairy Sci. 94:940-950.

Kononoff, P. J., A. J. Heinrichs, and D. R. Buckmaster. 2003. Modification of Penn State forage and total mixed ration particle separator and the effects of moisture content on its measurements. J. Dairy Sci. 86:1858-1863.

Lindström, T., and I. Redbo. 2000. Effect of feeding duration and rumen fill on behaviour in dairy cows. Appl. Anim. Behav. Sci. 70:83-97.

Longenbach, J. I., A. J. Heinrichs, and R. E. Graves. 1999. Feed bunk length requirements for Holstein dairy heifers. J. Dairy Sci. $82: 99-109$

Moody, M. L., G. I. Zanton, J. M. Daubert, and A. J. Heinrichs. 2007. Nutrient utilization of differing forage-to-concentrate ratios by growing Holstein heifers. J. Dairy Sci. 90:5580-5586.

Morris, T. R. 1999. Experimental Design and Analysis in Animal Sciences. CABI Publishing, New York, NY.

National Research Council. 2001. Nutrient Requirements for Dairy Cattle. 7th rev. ed. Natl. Acad. Sci., Washington, DC.

Redbo, I., M. Emanuelson, K. Lundberg, and N. Oredsson. 1996. Feeding level and oral stereotypies in dairy cows. Anim. Sci. 62:199206.

SAS Institute. 2003. User's Guide: Statistics. Version 9.1.3 ed. SAS Institute Inc., Cary, NC.

Van Soest, P. J., J. B. Robertson, and B. A. Lewis. 1991. Methods for dietary fiber, neutral detergent fiber and nonstarch polysaccharide in relation to animal nutrition. J. Dairy Sci. 74:3583-3597.

von Keyserlingk, M. A. G., J. Rushen, A. M. de Passillé, and D. M. Weary. 2009. Invited review: The welfare of dairy cattle - Key concepts and the role of science. J. Dairy Sci. 92:4101-4111. 